\title{
Association of dietary $\omega-3$ and $\omega-6$ fatty acids intake with cognitive performance in older adults: National Health and nutrition examination Survey (NHANES) 2011-2014
}

Xue Dong, Shiru Li, Jiahao Chen, Yan Li, Yanjun Wu and Dongfeng Zhang

\begin{abstract}
Background: Current evidence on the association of dietary $\omega-3$ and $\omega-6$ fatty acids intake with cognitive performance is inconsistent. Therefore, the aim is to explore the association of dietary $\omega-3$ and $\omega-6$ fatty acids intake with cognitive performance in the U.S. noninstitutionalized population of older adults.

Methods: We used data from the National Health and Nutrition Examination Survey (NHANES) 2011-2014. Intakes of $\omega-3$ and $\omega-6$ fatty acids were obtained through two 24-h dietary recalls and were adjusted by energy. Cognitive performance was evaluated by the Consortium to Establish a Registry for Alzheimer's disease (CERAD) Word Learning sub-test, Animal Fluency test and Digit Symbol Substitution Test (DSST). For each cognitive test, people who scored lower than the lowest quartile in each age group were defined as having low cognitive performance. Binary logistic regression and restricted cubic spline models were applied to evaluate the association of dietary $\omega-3$ and $\omega-6$ fatty acids intake with cognitive performance.

Results: A total of 2496 participants aged 60 years or older were included. In the full-adjusted model, the odds ratios (ORs) with 95\% confidence interval (Cl) of CERAD test score, Animal Fluency test score and DSST test score were $0.58(0.38-0.88), 0.68(0.47-0.99)$ and 0.59 (0.37-0.92) for the highest versus lowest tertile of dietary $\omega-3$ fatty acids intake, respectively; the ORs with $95 \% \mathrm{Cl}$ of CERAD test score, Animal Fluency test score and DSST test score were $0.48(0.31-0.75), 0.60(0.40-0.92)$ and $0.50(0.34-0.75)$ for the highest versus lowest tertile of dietary $\omega-6$ fatty acids intake, respectively. The association between $\omega-6: \omega-3$ ratio and cognitive performance was not statistically significant in three tests. In dose-response relationship analysis, L-shaped associations were apparent for $\omega$-3 and $\omega$ 6 fatty acids intake with CERAD test score, Animal Fluency test score and DSST test score.
\end{abstract}

Conclusions: Dietary $\omega-3$ and $\omega-6$ fatty acids intake might be inversely associated with low cognitive performance. Keywords: Cognitive performance, Dietary $\omega-3$ fatty acids, Dietary $\omega-6$ fatty acids, $\omega-6: \omega-3$ ratio, Dose-response

\footnotetext{
*Correspondence: zhangdf1961@126.com

Department of Epidemiology and Health Statistics, School of Public Health, Qingdao University, 38 Deng Zhou Street, Qingdao 266021, Shandong

Province, China
}

(c) The Author(s). 2020 Open Access This article is licensed under a Creative Commons Attribution 4.0 International License, which permits use, sharing, adaptation, distribution and reproduction in any medium or format, as long as you give appropriate credit to the original author(s) and the source, provide a link to the Creative Commons licence, and indicate if changes were made. The images or other third party material in this article are included in the article's Creative Commons licence, unless indicated otherwise in a credit line to the material. If material is not included in the article's Creative Commons licence and your intended use is not permitted by statutory regulation or exceeds the permitted use, you will need to obtain permission directly from the copyright holder. To view a copy of this licence, visit http://creativecommons.org/licenses/by/4.0/ The Creative Commons Public Domain Dedication waiver (http://creativecommons.org/publicdomain/zero/1.0/) applies to the data made available in this article, unless otherwise stated in a credit line to the data. 


\section{Introduction}

As life expectancy increases, the number of elderly people is growing worldwide. It is estimated that the number of the elderly aged 65 years or older in the U.S. grows by $15 \%$, and the number of the elderly aged 85 years or older grows even more by $30 \%$ between 2000 and 2010 [1]. Age-related cognitive decline can be a major health challenge for the elderly population, cognitive health has emerged as an important public health concern for America's aging population [2]. In America, approximately $36 \%$ of people are cognitively impaired, and 5.1 million people have dementia, with an expected doubling by 2050 [3]. The financial burden of dementia has already far exceeded the costs of cardiovascular and cancer diseases $[4,5]$. In 2015, the global cost of dementia was $\$ 9575.6$ billion and it is estimated to reach $\$ 2.54$ trillion in 2030 and $\$ 9.12$ trillion in 2050 [6]. The irreversibility of dementia, the lack of effective treatment and heavy financial burden make it imperative to prevent and treat low cognitive performance. Thus, developing measures to reduce the prevalence of low cognitive performance as well as treatments of diagnosed dementia have high priority in society [7].

Previous studies have shown that cognitive performance was determined by both genetic and environmental factors [8-15]. For instance, fruits and vegetables [16], vitamin D [13], vitamin B, protein, folate [11, 12] and polyphenols [17] have been proved to have protective effects on cognitive function, whereas some studies $[14,15]$ indicated that high level of saturated fat and refined sugar were associated with impaired cognitive performance.

Polyunsaturated fatty acids(PUFAs)are essential to human body functions because they can improve the activity of brain cells, enhance the memory and thinking abilities, and help reduce cardiovascular and cerebrovascular diseases [18-20]. But some studies have pointed out that $\omega-3$ and $\omega-6$ fatty acids intake may play a role in the pathogenesis of cognitive decline due to the prevailing mechanisms such as oxidative stress, inflammation, and vascular risk factors $[21,22]$. However, several studies have suggested that $\omega-3$ and $\omega-6$ fatty acids and their ratio could be associated with cognitive performance among elderly people [23-25]. Specifically, a low ratio of $\omega-6$ to $\omega-3$ fatty acids in the diet might reduce the risk of cognitive decline [26, 27].

To date, epidemiological studies which investigated the association of $\omega-3$ and $\omega-6$ fatty acids intake with cognitive performance in older Americans are scarce during NHANES examination in 2011-2012 and 2013-2014, and the results for the association of $\omega-3$ and $\omega-6$ fatty acids intake with cognitive performance are not entirely consistent [28-31]. Therefore, we analyzed a dataset of Americans aged 60 years or older from NHANES to investigate the association of $\omega-3$ and $\omega-6$ fatty acids intake and $\omega-6$ : $\omega-3$ ratio with cognitive performance.

\section{Materials and methods}

\section{Data collection and study population}

The NHANES is a 2-year-cycle cross-sectional survey conducted by the Centers for Disease Control and Prevention (CDC) of America, which aims to evaluate the health and nutritional status of the U.S. population. Representative samples of the non-institutional U.S. population are selected by a complex multi-stage probabilistic sampling design. Participants were interviewed at home firstly and then completed the health examination in a mobile examination center (MEC) [32]. The NHANES database is a publicly available dataset used by people worldwide [33]. All participants have provided informed consent both before the interview and examination stages.

A total of 19,931 individuals participated in the NHANES during 2011-2014, and our analyses were limited to 3632 individuals aged 60 years or older. Among them, we excluded participants with incomplete cognitive testing $(n=698)$, incomplete or unreliable 24-h recall data $(n=410)$ and missing weight data $(n=19)$. Individuals who had extreme total energy intakes of $<500$ or $>5000$ $\mathrm{kcal} /$ day for women, and $<500$ or $>8000 \mathrm{kcal} /$ day for men $(n=9)$ were further omitted. After exclusions, this study contained a total of 2496 participants aged 60 years or older (1204 men and 1292 women) (Fig. 1).

\section{Cognitive performance assessment}

A series of assessments for cognitive performance in NHANES were used in 2011-2014 and cognitive testing was performed among participants aged 60 years or older [32]. Cognitive performance was assessed in a household interview or a Mobile Examination Center (MEC) and was evaluated by the Consortium to Establish a Registry for Alzheimer's disease (CERAD) Word Learning sub-test, the Animal Fluency test and the Digit Symbol Substitution Test (DSST). These tests, which have been used in large screenings, epidemiological and clinical studies [34-39], evaluated working memory, language, processing speed, and executive functioning in older adults. Participants were asked for consent to audio-record the administration for quality control purpose. For interviews in English and Spanish, two interviewers transcribed verbatim responses from the audio recordings and scored the CERAD test, Animal fluency test and DSST test. Transcription and scoring usually were done on the same day assessments were conducted. Tests conducted in Korean, Vietnamese and Chinese were transcribed verbatim and scored by consultants in those languages later. Inconsistent scores were adjudicated by a third party, as necessary. In addition, review of the audio-recordings of assessments were evaluated for consistency of interviewer instructions and to determine test score accuracy. Approximately 10\% of recorded interviews were independently reviewed during data collection [40]. 


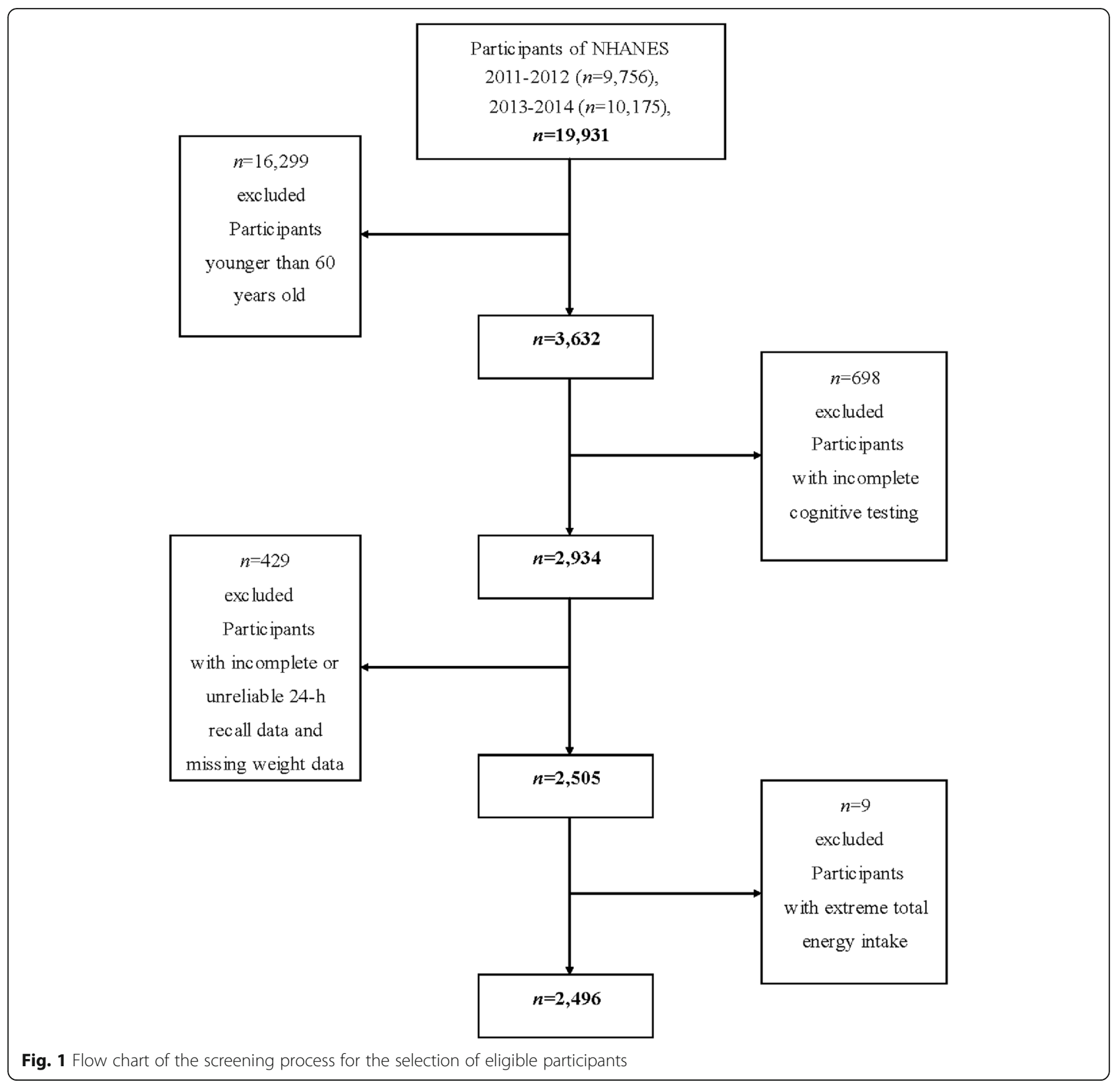

The CERAD test consisted of three consecutive learning trials as well as a delayed recall, which were designed to assess immediate and delayed learning ability for new verbal information, respectively. For the learning trials, participants were organized to read aloud 10 unrelated words when they were presented one at a time. Immediately following the introduction of the words, participants recalled as many words as possible. The order of the 10 words was altered in each of the three learning trials. The delayed word recall occurred after Animal Fluency and DSST tests were completed. The score on each trial ranged from 0 to 10 , and the total score of the CERAD test was the sum of three learning trials and a delayed recall trial. As a component of executive function, the Animal Fluency test examined categorical verbal fluency, participants were called upon to name as many animals as possible in $1 \mathrm{~min}$. The score was the sum for the number of correct answers. The DSST test, a performance module from the Wechsler Adult Intelligence Scale, was used to assess processing speed, sustained attention and working memory. The exercise was performed using a piece of paper with a key at the top pairing numbers with nine symbols. Participants have $2 \mathrm{~min}$ to copy the corresponding symbols from the key into 133 numbered boxes. The score, ranging from 0 to 133 , was the sum for the number of correct matches. 
Higher scores were linked to better cognitive performance for all tests.

Currently, there is not a gold standard cut-off point for the CERAD, DSST and Animal Fluency test to identify low cognitive performance. Therefore, we used the 25th percentile of the score, the lowest quartile, as the cut-off point, which is consistent with methods used in the published literature [41]. Furthermore, considering that age has a significant effect on cognitive performance, the score was further categorized based on age (60 to $<70$ years, 70 to $<80$ years, and $\geq 80$ years). For each cognitive test, people who scored lower than the lowest quartile in each age group were defined as having low cognitive performance.

\section{Dietary intake assessment}

Dietary $\omega-3$ and $\omega-6$ fatty acids intakes were obtained from two 24-h dietary recall interviews. The primary dietary interview was collected in-person in the mobile examination center (MEC), a follow-up dietary interview was conducted by telephone from the home office. Trained interviewers conducted dietary recall interviews using an automated data collection system during the MEC examination. At the end of the MEC dietary interview, the interviewers would schedule the participants for a phone follow-up (PFU) interview 3-10 days later. Dietary telephone interviewers at the home office would conduct the PFU interviews. Detailed descriptions of dietary interview and data processing procedures could be found under the dietary interview components on the NHANES website [42].

Ultimately, in our analyses, octadecatrienoic acid (18: 3 ), octadecatetraenoic acid (18:4), eicosapentaenoic acid (20:5), docosapentanoic acid (22:5), and docosahexaenoic acid (22:6) were included in $\omega-3$ fatty acids, meanwhile octadecadienoic acid (18:2) and eicosatetraenoic acid (20:4) were included in $\omega-6$ fatty acids [43]. The average daily $\omega-3$ and $\omega-6$ fatty acids intake were calculated according to the U.S. Department of Agriculture's Dietary Study Food and Nutrition Database for Dietary Studies [44] and were adjusted to total energy. Dietary $\omega-3$ and $\omega-6$ fatty acids intake $(\mathrm{mg} / \mathrm{kcal} /$ day $)$ and $\omega-6: \omega-3$ ratio were divided into tertiles, $\omega-3$ and $\omega-6$ intake was calculated from dietary intake only, supplement use was not collected in the NHANES 2011-2014.

\section{Covariates}

In addition to dietary $\omega-3$ and $\omega-6$ fatty acids intake, we investigated some potential confounding factors, which included: age (60-70 years, $70-80$ years, and $\geq 80$ years), gender (Male and Female), race (Mexican American, other Hispanic, Non-Hispanic White, Non-Hispanic Black, and other race), educational level (Below high school, High school, and Above high school), marital status (Married/
Living with partner and Widowed/Divorced/Separated/ Never married), body mass index (BMI) (normal: $<25 \mathrm{~kg} /$ $\mathrm{m}^{2}$; overweight: 25 to $<30 \mathrm{~kg} / \mathrm{m}^{2}$; obese: $\geq 30 \mathrm{~kg} / \mathrm{m}^{2}$ ) and drinking (Having at least 12 alcohol drinks per year or not).

The physical activity questionnaire is based on the Global Physical Activity Questionnaire (GPAQ), and the questions were asked using the computer-assisted personal interview software [45]. The main outcomes of physical activity were defined using the following questions: (1) Vigorous work activity: "Does your work involve vigorous-intensity activity that causes large increases in breathing or heart rate like carrying or lifting heavy loads, digging or construction work for at least 10 minutes continuously?" (yes, no); (2) Moderate work activity: "Does your work involve moderate-intensity activity that causes small increases in breathing or heart rate such as brisk walking or carrying light loads for at least 10 minutes continuously?" (yes, no); (3) Vigorous recreational activity: "Do you do any vigorous-intensity sports, fitness, or recreational activity that cause large increases in breathing or heart rate like running or basketball for at least 10 minutes continuously?" (yes, no); (4) Moderate recreational activity: "Do you do any moderate-intensity sports, fitness, or recreational activity that cause a small increase in breathing or heart rate such as brisk walking, bicycling, swimming, or volleyball for at least 10 minutes continuously?" (yes, no). Participants were labelled as "vigorous work activity" if the answer for question (1) was yes, "moderate work activity" if the answer for question (1) was no and question (2) was yes, "other" if the answer for question (1) and question (2) were both no. The same was true for recreational activity. Poverty income ratio (PIR) - the ratio of family income to the poverty threshold - was used to define income. The Department of Health and Human Services (HHS) poverty guidelines were used as the poverty measure to calculate this ratio [46]. PIR was divided into two levels $(\leq 0.99, \geq 1)$. A ratio of 0.99 or less indicated that family income was below the poverty level, while a ratio of 1 or greater implied that family income was at or above the poverty level. History of hypertension, diabetes or stroke was defined as self-reported physician diagnosis of hypertension, diabetes or stroke.

\section{Statistical analysis}

All statistical analyses were conducted with Stata 15.0 (Stata Corporation, College Station, TX). Account for the complex sampling design and ensure nationally representative estimates, all analyses were adjusted for survey design and weighting variables. Because we combine two cycles of the NHANES data, new sample weights (the original 2-year sample weight divided by 2) was constructed according to the analytical guidelines of the NHANES [47]. Kolmogorov-Smirnov normality test was 
adopted to test the normality of continuous variables and we described normally distributed variables with mean \pm standard deviation, non-normal distributed variables with median (interquartile range). Student's t-tests was utilized to compare the mean levels between low cognitive performers and not low cognitive performers if the variable was normally distributed, otherwise, the Mann-Whitney $\mathrm{U}$ test was adopted. When comparing the percentages of categorical variables between low cognitive performers and not low cognitive performers, we choose Chi-square tests. Dietary $\omega-3$ and $\omega-6$ fatty acids intake and $\omega-6: \omega-3$ ratio were categorized based on tertiles (tertile 1 : $<33$ th percentile, tertile $2: \geq 33$ to 67 th percentile, tertile 3 : $\geq 67$ th percentile) with tertile 1 as the reference category. Cognitive performance was analyzed as a binary variable. We conducted binary logistic regression analyses to examine the association of dietary $\omega-3$ and $\omega-6$ fatty acids intake and $\omega-6: \omega-3$ ratio with cognitive performance. Model 1 adjusted for age and gender. Model 2 was additionally adjusted for race, educational level, marital status, poverty income ratio, body mass index, recreational activity, work activity, drinking status, diabetes, hypertension and stroke. We analyzed the multicollinearity of the logistic regression. The tolerance was greater than 0.1 , and the variance inflation factor (VIF) was less than 10, so there was no multicollinearity. We further used restricted cubic spline with 3 knots located at the 5th, 50th, and 95th percentiles of the exposure distribution to assess dose-response relationship in the logistic regression model 2. The $p$-value for non-linearity was calculated by testing the value of the coefficient of the second spline of zero [48]. A two-sided $p<0.05$ was considered statistically significant.

\section{Results}

Table 1 presents the characteristics of the study population across cognitive status. Ultimately, a total of 2496 participants were included in the study. There were significant differences between people with low cognitive performance and normal cognitive performance in the distribution of race, educational level, poverty income ratio, work activity, recreational activity, stroke, diabetes and total $\omega-6$ fatty acids intake among CERAD test, Animal Fluency test and DSST test. People with low cognitive performance tended to have lower educational level, poverty income ratio, work activity, recreational activity, total $\omega-6$ fatty acids intake, and higher prevalence of stroke and diabetes than people with normal cognitive performance. Higher age was associated with lower cognitive performance in Animal Fluency test. The prevalence of hypertension in people with low cognitive performance with Animal Fluency and DSST test was significantly higher than that of people with normal cognitive performance. Alcohol drinking rate was significantly lower in people with low cognitive performance with Animal Fluency and DSST test than people with normal cognitive performance. People with low cognitive performance with CERAD and DSST test were more likely to be male and have less $\omega-3$ fatty acids intake. People with low cognitive performance with CERAD test tended to have lower ratio of $\omega-6$ to $\omega-3$ fatty acids.

Table 2 shows the associations between dietary $\omega-3$ fatty acids intake, dietary $\omega-6$ fatty acids intake, $\omega-6: \omega-3$ ratio and CERAD test score. The crude ORs with $95 \%$ CI of CERAD test score were $0.54(0.38-0.77)$ and 0.41 $(0.27-0.63)$ in the highest versus lowest tertile of dietary $\omega-3$ and $\omega-6$ fatty acids intake, respectively. After adjustment for age and gender, $\omega-3$ and $\omega-6$ fatty acids intake were still inversely associated with low cognitive performance. In model 2, the multivariate adjusted ORs with $95 \% \mathrm{CI}$ of CERAD test score were $0.58(0.38-0.88)$ and $0.48(0.31-0.75)$ in the highest versus lowest tertile of dietary $\omega-3$ and $\omega-6$ fatty acids intake, respectively. The association between $\omega-6: \omega-3$ ratio and CERAD test score was not statistically significant.

The associations between dietary $\omega-3$ fatty acids intake, dietary $\omega-6$ fatty acids intake, $\omega-6: \omega-3$ ratio and Animal Fluency test score are presented in Table 3 . In logistic regression analyses, the crude ORs with 95\% CI of Animal Fluency test score were $0.68(0.48-0.96)$ and $0.60(0.43-$ $0.84)$ in the highest versus lowest tertile of dietary $\omega-3$ and $\omega-6$ fatty acids intake, respectively. After adjustment for age and gender, $\omega-3$ and $\omega-6$ fatty acids intake were still inversely associated with low cognitive performance. In model 2, the multivariate adjusted ORs with $95 \%$ CI of Animal Fluency test score were $0.68(0.47-0.99)$ and 0.60 $(0.40-0.92)$ in the highest versus lowest tertile of dietary $\omega-3$ and $\omega-6$ fatty acids intake, respectively. The association between $\omega-6: \omega-3$ ratio and Animal Fluency test score was not statistically significant.

Table 4 shows the associations between dietary $\omega-3$ fatty acids intake, dietary $\omega-6$ fatty acids intake, $\omega-6: \omega-3$ ratio and DSST test score. The crude ORs with $95 \% \mathrm{CI}$ of DSST test score were 0.63 (0.43-0.91), 0.47 (0.32-0.68) and $0.71(0.53-0.93)$ in the highest versus lowest tertile of $\omega-3, \omega-6$ fatty acids intake and $\omega-6: \omega-3$ ratio, respectively. After adjustment for age and gender, the results were similar to the crude ORs ( $95 \% \mathrm{CIs}$ ). In model 2, the multivariate adjusted ORs $(95 \% \mathrm{CI})$ of DSST test score were $0.59(0.37-0.92)$ and $0.50(0.34-0.75)$ in the highest versus lowest tertile of dietary $\omega-3$ and $\omega-6$ fatty acids intake, respectively. The association between $\omega-6: \omega-3$ ratio and the DSST test score was not significant.

The results of the restricted cubic spline dose-response relationship analysis between dietary $\omega-3$ fatty acids intake, dietary $\omega-6$ fatty acids intake and CERAD test score were presented in Fig. 2. There was a nonlinear negative correlation and an L-shaped association between dietary $\omega-3$ fatty acids intake and CERAD test score (P for nonlinearity $=0.041$ ). Similarly, an L-shaped association between 
Table 1 Characteristics of the study population, NHANES 2011-2014 ( $N=2496)$

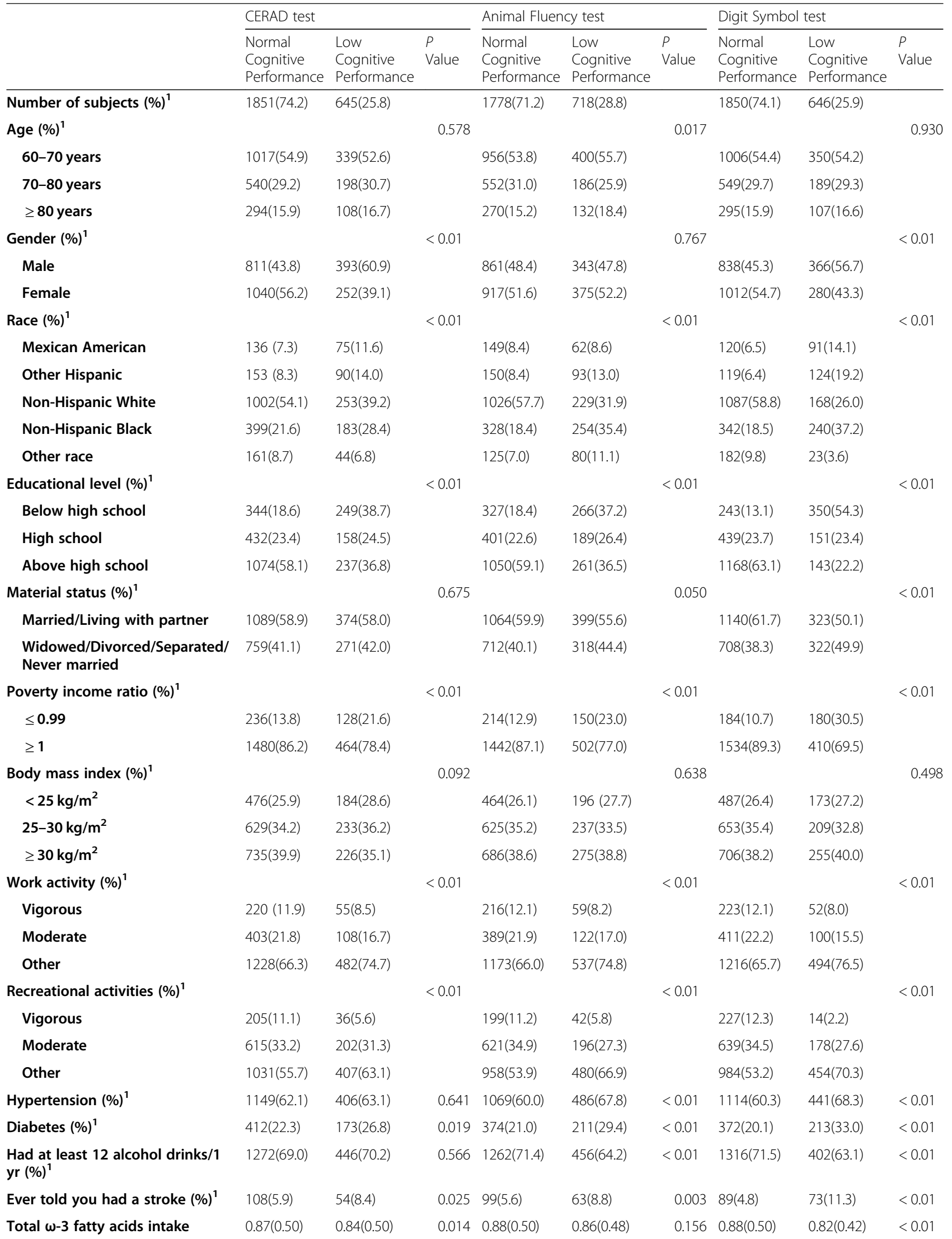


Table 1 Characteristics of the study population, NHANES 2011-2014 ( $N=2496)$ (Continued)

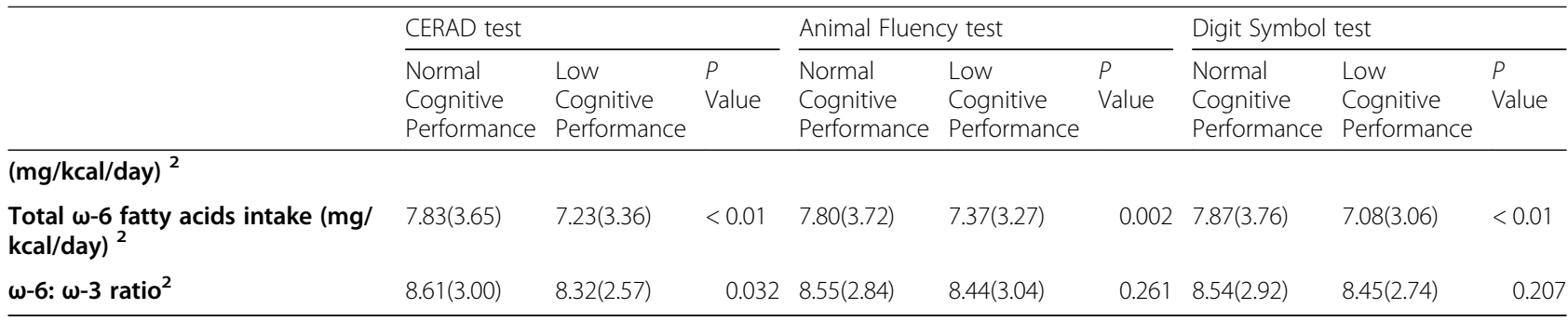

Data are number of subjects (percentage) or medians (inter quartile ranges)

${ }^{1}$ Chi-square test was used to compare the percentage between participants with and without low cognitive performance

${ }^{2}$ Mann-Whitney $U$ test was used to compare the mean values between participants with and without low cognitive performance

dietary $\omega-6$ fatty acids intake and CERAD test score was also found.

The results of the restricted cubic spline doseresponse relationship analysis between dietary $\omega-3$ fatty acids intake, dietary $\omega-6$ fatty acids intake and Animal Fluency test score were depicted in Fig. 3. There was an L-shaped correlation between dietary $\omega-3$ fatty acids intake and Animal Fluency test score, and no significant association was observed in Animal Fluency test score with an intake lower than $1.5 \mathrm{mg} / \mathrm{kcal} /$ day (OR: 0.50; 95\% CI: $0.25-0.99$ ) or beyond $1.9 \mathrm{mg} / \mathrm{kcal} /$ day (OR: 0.50 ; 95\% CI: $0.25-1.00)$. Meanwhile, there was also an Lshaped correlation between dietary $\omega-6$ fatty acids intake and Animal Fluency test score, and there was significant association in Animal Fluency test score at $<12 \mathrm{mg} / \mathrm{kcal} /$ day (OR: 0.39; 95\% CI: 0.16-0.99).

The results of the restricted cubic spline analyses between dietary $\omega-3$ fatty acids intake, dietary $\omega-6$ fatty acids intake and DSST test score were depicted in Fig. 4. An L-shaped association between dietary $\omega$-3 fatty acids intake and DSST test score was found. No significant association was observed in DSST test score with an intake lower than $1.3 \mathrm{mg} / \mathrm{kcal} /$ day (OR: 0.52; 95\% CI: $0.27-$ 1.00 ) or beyond $1.7 \mathrm{mg} / \mathrm{kcal} /$ day (OR: 0.50 ; $95 \% \mathrm{CI}$ : 0.26-0.97). There was a linear negative correlation between dietary $\omega-6$ fatty acids intake and DSST test score, and there was significant association in DSST test score at $>11 \mathrm{mg} / \mathrm{kcal} /$ day (OR: 0.48; 95\% CI: 0.26-0.91).

\section{Discussion}

Cognitive performance has important implications for the U.S. aging population. This study explores the associations of dietary $\omega-3$ and $\omega-6$ fatty acids intake and $\omega-$ 6: $\omega-3$ ratio with cognitive performance among the U.S. population aged 60 years or older. In the full-adjusted model, the highest versus lowest tertile of dietary $\omega-3$ and $\omega-6$ fatty acids intake were inversely associated with CERAD test score, Animal Fluency test score and DSST test score, respectively. The association between $\omega-6: \omega$ 3 ratio and cognitive performance was not statistically

Table 2 Weighted odds ratios (95\% confidence intervals) for score on CERAD test across tertiles of dietary $\omega-3$ and $\omega-6$ fatty acids intake and $\omega-6: \omega-3$ ratio, NHANES 2011-2014 ( $N=2496)$

\begin{tabular}{|c|c|c|c|c|}
\hline & Case/Participants & Crude $^{1}$ & Model $1^{1}$ & Model $2^{1}$ \\
\hline \multicolumn{5}{|l|}{$\omega-3$ (mg/kcal/day) } \\
\hline$<0.727$ & $229 / 832$ & 1.00 (Ref.) & 1.00 (Ref.) & 1.00 (Ref.) \\
\hline 0.727 to $<1.04$ & 233/832 & $0.66(0.46-0.94) *$ & $0.66(0.46-0.94) *$ & $0.63(0.43-0.91) *$ \\
\hline$\geq 1.04$ & $183 / 832$ & $0.54(0.38-0.77)^{* *}$ & $0.55(0.38-0.78) * *$ & $0.58(0.38-0.88) *$ \\
\hline \multicolumn{5}{|l|}{$\omega-6$ (mg/kcal/day) } \\
\hline$<6.538$ & $253 / 832$ & 1.00 (Ref.) & 1.00 (Ref.) & 1.00 (Ref.) \\
\hline 6.538 to $<8.848$ & $217 / 832$ & $0.55(0.39-0.79) * *$ & $0.56(0.39-0.80) * *$ & $0.57(0.38-0.86)^{* *}$ \\
\hline$\geq 8.848$ & $175 / 832$ & $0.41(0.27-0.63) * *$ & $0.44(0.28-0.67)^{* *}$ & $0.48(0.31-0.75)^{* *}$ \\
\hline \multicolumn{5}{|l|}{$\omega-6: \omega-3$ ratio } \\
\hline$<7.684$ & $228 / 832$ & 1.00 (Ref.) & 1.00 (Ref.) & 1.00 (Ref.) \\
\hline 7.684 to $<9.462$ & 222/832 & $1.03(0.78-1.35)$ & $1.05(0.80-1.37)$ & $0.93(0.67-1.29)$ \\
\hline$\geq 9.462$ & 195/832 & $0.89(0.60-1.31)$ & $0.94(0.64-1.38)$ & $1.02(0.65-1.58)$ \\
\hline
\end{tabular}

${ }^{1}$ Calculated using binary logistic regression

Model 1 adjusted for age and gender

Model 2 adjusted for age and gender, race, educational level, marital status, income, BMI, recreational activity, work activity, drinking status, hypertension, diabetes and stroke

${ }^{*} p<0.05$; ${ }^{* *} p<0.01$ 
Table 3 Weighted odds ratios (95\% confidence intervals) for score on Animal Fluency test across tertiles of dietary $\omega-3$ and $\omega-6$ fatty acids intake and $\omega-6$ : $\omega-3$ ratio, NHANES 2011-2014 ( $N=2496)$

\begin{tabular}{|c|c|c|c|c|}
\hline & Case/Participants & Crude $^{1}$ & Model $1^{1}$ & Model $2^{1}$ \\
\hline \multicolumn{5}{|l|}{$\omega-3$ (mg/kcal/day) } \\
\hline$<0.727$ & $245 / 832$ & 1.00 (Ref.) & 1.00 (Ref.) & 1.00 (Ref.) \\
\hline 0.727 to $<1.04$ & $255 / 832$ & $0.77(0.55-1.05)$ & $0.75(0.54-1.03)$ & $0.75(0.54-1.03)$ \\
\hline$\geq 1.04$ & $218 / 832$ & $0.68(0.48-0.96) *$ & $0.67(0.48-0.94) *$ & $0.68(0.47-0.99)$ * \\
\hline \multicolumn{5}{|l|}{$\omega-6$ (mg/kcal/day) } \\
\hline$<6.538$ & $262 / 832$ & 1.00 (Ref.) & 1.00 (Ref.) & 1.00 (Ref.) \\
\hline 6.538 to $<8.848$ & $249 / 832$ & $0.69(0.47-1.03)$ & $0.69(0.46-1.03)$ & $0.66(0.43-1.02)$ \\
\hline$\geq 8.848$ & 207/832 & $0.60(0.43-0.84)^{* *}$ & $0.61(0.43-0.87)^{* *}$ & $0.60(0.40-0.92) *$ \\
\hline \multicolumn{5}{|l|}{$\omega-6: \omega-3$ ratio } \\
\hline$<7.684$ & $245 / 832$ & 1.00 (Ref.) & 1.00 (Ref.) & 1.00 (Ref.) \\
\hline 7.684 to $<9.462$ & 232/832 & $1.08(0.80-1.47)$ & $1.09(0.81-1.47)$ & $1.17(0.83-1.65)$ \\
\hline$\geq 9.462$ & $241 / 832$ & $1.01(0.70-1.45)$ & $1.04(0.71-1.53)$ & $1.15(0.73-1.81)$ \\
\hline
\end{tabular}

${ }^{1}$ Calculated using binary logistic regression

Model 1 adjusted for age and gender

Model 2 adjusted for age and gender, race, educational level, marital status, income, BMI, recreational activity, work activity, drinking status, hypertension,

diabetes and stroke

${ }^{*} p<0.05 ;{ }^{* *} p<0.01$

significant in three tests. In dose-response relationship analysis, L-shaped associations were apparent for $\omega-3$ and $\omega-6$ fatty acids intake with CERAD test score, Animal Fluency test score and DSST test score.

Some studies use age- and education-specific cut points when identifying low cognitive performers [49]. Because cognitive performance on average declines with age, a lower score for an older person could be considered impairment, when in fact, it is within the normal range of performance for people of that age. However, this impairment would be missed if the cut-point score for the lowest 25th percentile is calculated without considering age. Therefore, in this report, low performers are defined by cut points that are conditional on age. Similarly, a lower score for a person with less education may be considered cognitive impairment, when in fact, it does not represent a decline from previous levels. Considering the issue with education, we put education in the covariates when performed a regression analysis. According to the objective of a study, researchers may

Table 4 Weighted odds ratios (95\% confidence intervals) for score on Digit Symbol Substitution test across tertiles of dietary $\omega$-3 and $\omega-6$ fatty acids intake and $\omega-6: \omega-3$ ratio, NHANES 2011-2014 ( $N=2496)$

\begin{tabular}{|c|c|c|c|c|}
\hline & Case/Participants & Crude $^{1}$ & Model $1^{1}$ & Model $2^{1}$ \\
\hline \multicolumn{5}{|l|}{$\omega-3$ (mg/kcal/day) } \\
\hline$<0.727$ & 243/832 & 1.00 (Ref.) & 1.00 (Ref.) & 1.00 (Ref.) \\
\hline 0.727 to $<1.04$ & 232/832 & $0.88(0.61-1.24)$ & $0.86(0.60-1.21)$ & $0.93(0.57-1.51)$ \\
\hline$\geq 1.04$ & $171 / 832$ & $0.63(0.43-0.91) *$ & $0.62(0.42-0.88) *$ & $0.59(0.37-0.92) *$ \\
\hline \multicolumn{5}{|l|}{ w-6 (mg/kcal/day) } \\
\hline$<6.538$ & $254 / 832$ & 1.00 (Ref.) & 1.00 (Ref.) & 1.00 (Ref.) \\
\hline 6.538 to $<8.848$ & 235/832 & $0.76(0.56-1.01)$ & $0.76(0.57-1.02)$ & $0.78(0.51-1.18)$ \\
\hline$\geq 8.848$ & 157/832 & $0.47(0.32-0.68) * *$ & $0.49(0.33-0.71) * *$ & $0.50(0.34-0.75) * *$ \\
\hline \multicolumn{5}{|l|}{$\omega-6: \omega-3$ ratio } \\
\hline$<7.684$ & $223 / 832$ & 1.00 (Ref.) & 1.00 (Ref.) & 1.00 (Ref.) \\
\hline 7.684 to $<9.462$ & $228 / 832$ & $1.05(0.73-1.51)$ & $1.06(0.74-1.52)$ & $1.01(0.66-1.57)$ \\
\hline$\geq 9.462$ & 195/832 & $0.71(0.53-0.93) *$ & $0.74(0.55-0.99) *$ & $0.86(0.54-1.36)$ \\
\hline
\end{tabular}

1Calculated using binary logistic regression

Model 1 adjusted for age and gender

Model 2 adjusted for age and gender, race, educational level, marital status, income, BMI, recreational activity, work activity, drinking status, hypertension, diabetes and stroke

${ }^{*} p<0.05 ;{ }^{* *} p<0.01$ 

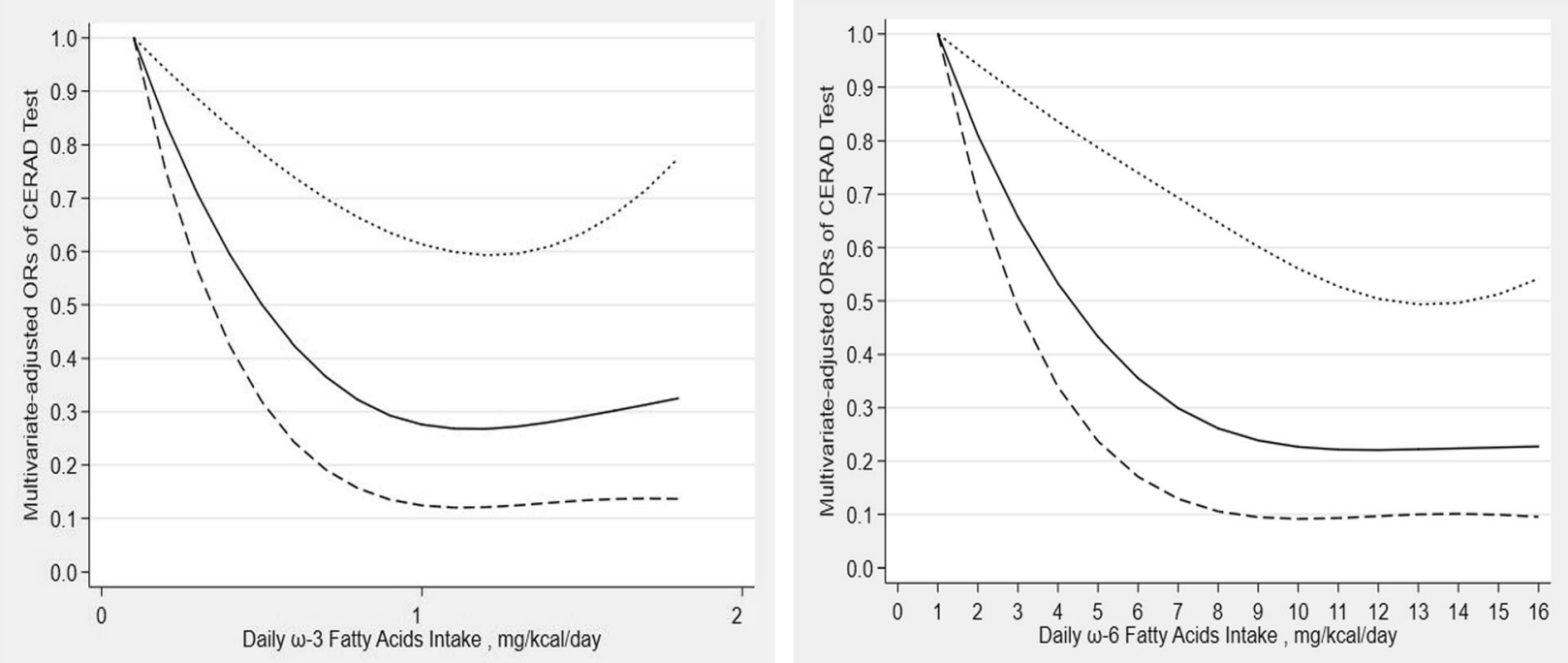

Fig. 2 Dose-response relationship between $\omega-3$ and $\omega-6$ fatty acids intake and cognitive functioning in CERAD test. The association was adjusted for age, gender, race, educational level, marital status, income, BMI, recreational activity, work activity, drinking status, hypertension, diabetes and stroke. The solid line and dash line represent the estimated ORs and its 95\% confidence intervals. (OR, odds ratio)

choose to control various factors and use different cut points.

The results of our study were consistent with some previous studies [30, 50-53]. Fotuhi et al. [50] found the intake of $\omega-3$ fatty acids could reduce the risk of cognitive decline in elderly individuals. Moreover, a 2-year followup study performed by Sandra Kalmijn et al. [51] as well as a 3-year follow-up study conducted by Beydoun [30] also indicated this negative association between $\omega-3$ fatty acids and cognitive decline. Nevertheless, some results were inconsistent with previous studies. Some studies [29, $31]$ indicated that there was no significant association between $\omega-3$ fatty acids intake and cognitive impairment. Our study found the intake of $\omega-6$ fatty acids might be inversely associated with low cognitive performance, and the study conducted by Das et al. [53] also illuminated this negative association. In contrast, Arendash et al. [31] stated that high level of $\omega-6$ fatty acids were associated with cognitive impairment. There was no significant association between the ratio of $\omega-6$ to $\omega-3$ fatty acids and
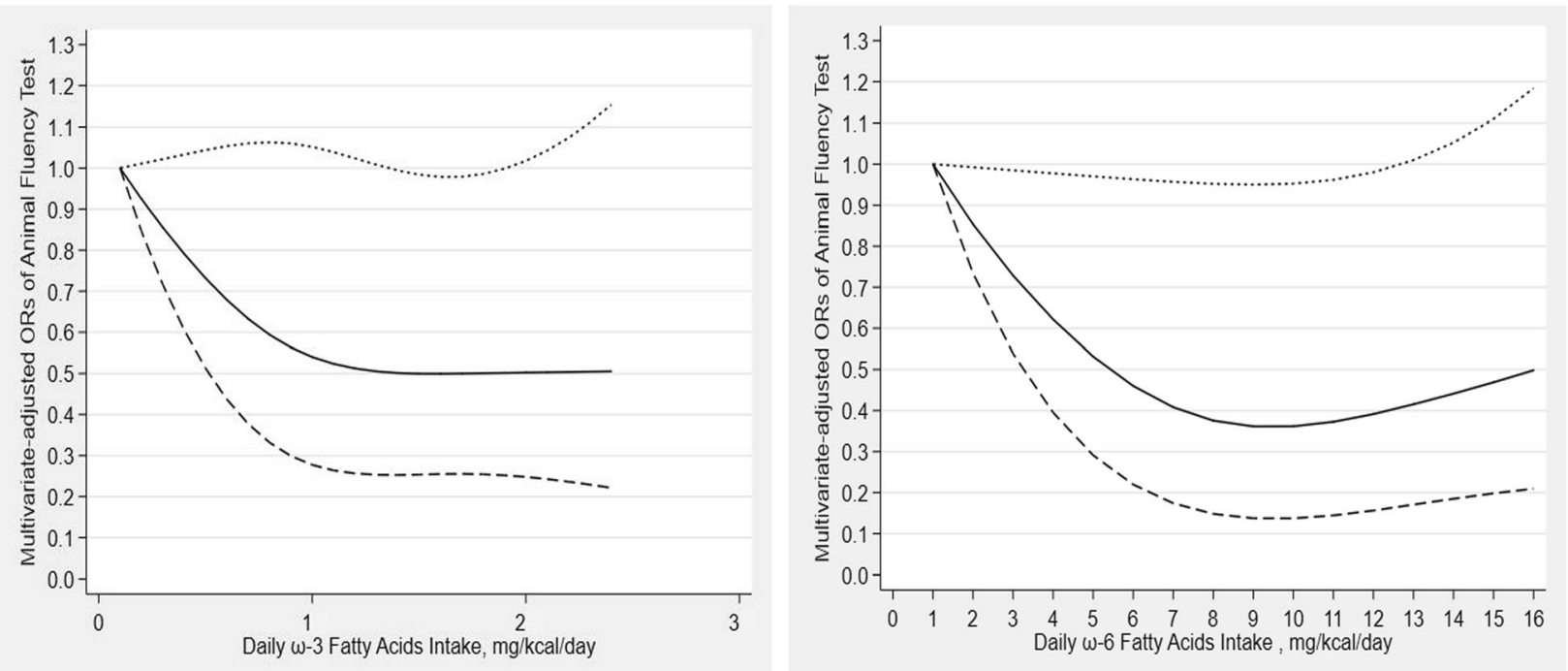

Fig. 3 Dose-response relationship between $\omega-3$ and $\omega-6$ fatty acids intake and cognitive functioning in Animal Fluency test. The association was adjusted for age, gender, race, educational level, marital status, income, BMl, recreational activity, work activity, drinking status, hypertension, diabetes and stroke. The solid line and dash line represent the estimated ORs and its 95\% confidence intervals. (OR, odds ratio) 

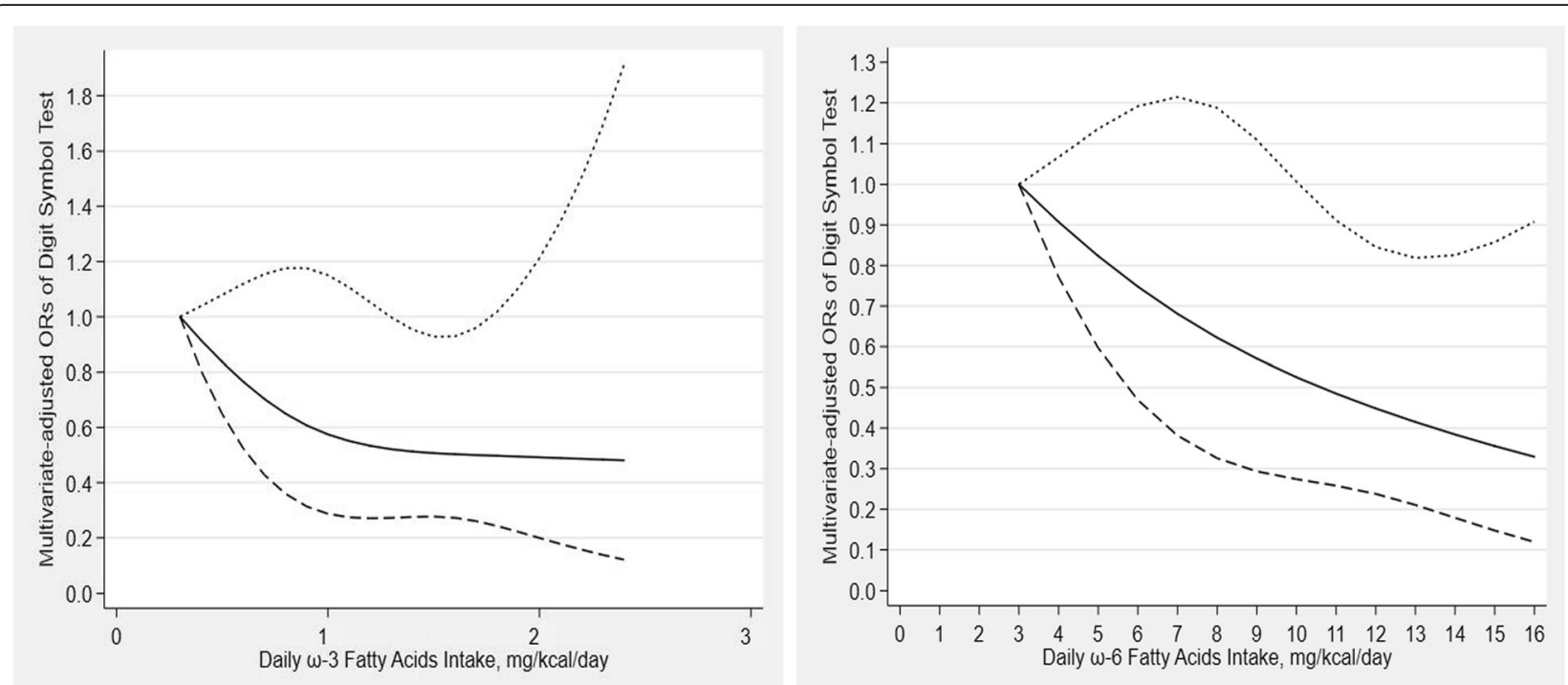

Fig. 4 Dose-response relationship between $\omega-3$ and $\omega-6$ fatty acids intake and cognitive functioning in Digit Symbol test. The association was adjusted for age, gender, race, educational level, marital status, income, BMI, recreational activity, work activity, drinking status, hypertension, diabetes and stroke. The solid line and dash line represent the estimated ORs and its 95\% confidence intervals. (OR, odds ratio)

cognitive performance in our study, whereas Andruchow et al. and Sheppard et al. [28, 54] found a low level of $\omega-6$ : $\omega-3$ ratio in the diet might be inversely associated with the risk of cognitive decline in older adults.

The mechanisms of the relationship between dietary $\omega$ 3 and $\omega-6$ fatty acids intake and cognitive performance remain unclear, but there have been several possibilities. First of all, $\omega-3$ fatty acids may play an important role in the transmission of ions and neurotransmitters inside and outside of nerve cells [55]. If $\omega-3$ fatty acids are insufficient, they will be replaced by other kinds of fatty acids, which may reduce the fluidity of the cell membrane, damage synapses and dendrites [56] and disrupt the concentration of neurotransmitters inside and outside of nerve cells, thus having a serious impact on brain function. Second, $\omega-3$ fatty acids increase cell viability through neuroprotective and anti-apoptotic mechanisms [57], and they may reduce neuronal oxidative stress. Third, $\omega-3$ fatty acids can promote neurogenesis and long term potential (LTP) formation in the hippocampus [58], and improve the function of the hippocampus. Calderon et al. [59] also found that $\omega-3$ fatty acids could promote the survival of hippocampal neurons, and increase the number and length of neuronal processes significantly. Fourth, the $\omega-3$ fatty acids may produce an anti-inflammatory effect [22], that is, they can reduce the production of proinflammatory cytokines in humans [60], and inflammatory reaction is of great significance in the development and progression of cognitive decline. The mechanism of $\omega-6$ fatty acids is unclear. Therefore, further research is required to explore the relationship between $\omega-6$ fatty acids intake and cognitive performance.
Our study presents several advantages. First, we used a large nationally representative sample of older adults in the US, which increased the statistical power to provide a more reliable result. Second, we investigated the doseresponse relationship between dietary $\omega-3$ and $\omega-6$ fatty acids intake and cognitive performance. Third, we adjusted for some potential confounding factors in the process of exploring the associations of $\omega-3$ and $\omega-6$ fatty acids intake with cognitive performance.

Our study has several limitations. Primarily, as a crosssectional study, it was difficult to ascertain causality. Furthermore, although we have adjusted for some confounders, we cannot rule out the potential confounding bias from unmeasured confounders. Participants who had mental or physical conditions that could influence performance, or used medications that may be associated with cognitive performance were not excluded from this analysis. What's more, because NHANES data measured cognitive performance only at one point in time and in selected domains, these measures could not replace a diagnosis based on a clinical examination. The cognitive tests, chosen for ease of administration, availability, and use in other surveys, did not cover all domains of cognition. Adults who performed well in one domain may not perform well in another domain. Finally, the dietary data were obtained from two 24-h dietary recall interviews, which could not accurately reflect individuals' usual intake.

\section{Conclusions}

In conclusion, our study suggests that dietary $\omega-3$ and $\omega-6$ fatty acids intake might be inversely associated with 
low cognitive performance for participants aged 60 years or older in the U.S. The associations we investigated in this study are biologically plausible, and these findings are required to be confirmed by further large-scale prospective studies.

\section{Abbreviations}

PUFAs: Polyunsaturated fatty acids; NHANES: The National Health and Nutrition Examination Surveys; CERAD: The Consortium to Establish a Registry for Alzheimer's disease; DSST: The Digit Symbol Substitution Test; GPAQ: The Global Physical Activity Questionnaire; PIR: Poverty income ratio; HHS: The Department of Health and Human Services; MEC: Mobile examination center; PFU: Phone follow-up; BMI: Body mass index; OR: Odds ratio; Cl: Confidence interval

\section{Acknowledgments}

This research did not receive any specific grant from funding agencies in the public, commercial, or not-for-profit sectors.

We acknowledge the staff at the National Center for Health Statistics at the CDC, who design, collect, administer the NHANES data and release the data available for public use.

We are thankful to all study participants for their cooperation.

\section{Authors' contributions}

XD and DZ conceived and designed the study; XD, JC and SL analyzed the data; XD and DZ wrote the paper; DZ reviewed the manuscript and had primary responsibility for the final content. All authors provided critical revisions of the manuscript and approved the final manuscript.

\section{Funding}

This research did not receive any specific grant from funding agencies in the public, commercial, or not-for-profit sectors.

\section{Availability of data and materials}

The datasets supporting the conclusions of this article are available in publicly repository as described below. The authors do not own the data. National Health and Nutrition Examination Survey data are available from the National Center for Health Statistics (http://www.cdc.gov/nchs/nhanes/ nhanes_questionnaires.htm).

\section{Ethics approval and consent to participate}

Not applicable.

\section{Consent for publication}

Not applicable.

\section{Competing interests}

The authors declare that they have no competing interests.

Received: 3 December 2019 Accepted: 23 March 2020

Published online: 28 March 2020

\section{References}

1. Jones DS, Podolsky SH, Greene JA. The burden of disease and the changing task of medicine. N Engl J Med. 2012;366:2333-8. https://doi.org/10.1056/ NEJMp1113569.

2. Centers for Disease Control and Prevention. The Healthy Brain Initiative: The Public Health Road Map for State and National Partnerships, 2013-2018, Interim Progress Report; Atlanta: CDC, 2015. https://www.cdc.gov/aging/ pdf/2013-healthy-brain-initiative-interim-report.pdf Accessed 2 February 2020.

3. Hebert LE, Weuve J, Scherr PA, Evans DA. Alzheimer disease in the United States (2010-2050) estimated using the 2010 census. Neurology. 2013;80: 1778-83. https://doi.org/10.1212/WNL.0b013e31828726f5.

4. Tabert MH, Albert SM, Borukhova-Milov L, Camacho Y, Pelton G, Liu X, et al. Functional deficits in patients with mild cognitive impairment: prediction of AD. Neurology. 2002;58:758-64. https://doi.org/10.1212/wnl.58.5.758.

5. Ernst RL, Hay JW. Economic research on Alzheimer disease: a review of the literature. Alzheimer Dis Assoc Disord. 1997;11(Suppl 6):135-45.
6. Jia J, Wei C, Chen S, Li F, Tang Y, Qin W, et al. The cost of Alzheimer's disease in China and re-estimation of costs worldwide. Alzheimers Dement. 2018;14:483-91. https://doi.org/10.1016/j.jalz.2017.12.006.

7. Cederholm T. Fish consumption and omega-3 fatty acid supplementation for prevention or treatment of cognitive decline, dementia or Alzheimer's disease in older adults - any news? Curr Opin Clin Nutr Metab Care. 2017;20: 104-9. https://doi.org/10.1097/MCO.0000000000000350.

8. Wu Y, Tian X, Pang Z, Li S, Tan Q. A genome-wide association study of cognitive function in Chinese adult twins. Biogerontology. 2017. https://doi. org/10.1007/s10522-017-9725-5.

9. Polderman TJ, Benyamin B, de Leeuw CA, Sullivan PF, van Bochoven A, Visscher PM, et al. Meta-analysis of the heritability of human traits based on fifty years of twin studies. Nat Genet. 2015;47:702-9. https://doi.org/10.1038/ ng.3285.

10. Xu C, Sun J, Duan H, Ji F, Tian X, Zhai Y, et al. Gene, environment and cognitive function: a Chinese twin ageing study. Age Ageing. 2015;44:4527. https://doi.org/10.1093/ageing/afv015.

11. Solfrizzi V, Custodero C, Lozupone M, Imbimbo BP, Valiani V, Agosti P, et al. Relationships of dietary patterns, foods, and micro- and macronutrients with Alzheimer's disease and late-life cognitive disorders: a systematic review. J Alzheimers Dis. 2017;59:815-49. https://doi.org/10.3233/JAD-170248.

12. Aridi YS, Walker $J$, Wright ORL. The association between the Mediterranean dietary pattern and cognitive Health: a systematic review. Nutrients. 2017;9. https://doi.org/10.3390/nu9070674.

13. Goodwill AM, Szoeke C. A systematic review and meta-analysis of the effect of low vitamin D on cognition. J Am Geriatr Soc. 2017;65:2161-8. https:// doi.org/10.1111/jgs.15012.

14. Freeman LR, Haley-Zitlin V, Rosenberger DS, Granholm AC. Damaging effects of a high-fat diet to the brain and cognition: a review of proposed mechanisms. Nutr Neurosci. 2014;17:241-51. https://doi.org/10.1179/ $1476830513 y .0000000092$.

15. Beilharz JE, Maniam J, Morris MJ. Diet-induced cognitive deficits: the role of fat and sugar, Potential Mechanisms and Nutritional Interventions. Nutrients. 2015;7:6719-38. https://doi.org/10.3390/nu7085307.

16. Zielinska MA, Bialecka A, Pietruszka B, Hamulka J. Vegetables and fruit, as a source of bioactive substances, and impact on memory and cognitive function of elderly. Postepy Hig Med Dosw. 2017;71:267-80.

17. Moore K, Hughes CF, Ward M, Hoey L, McNulty H. Diet, nutrition and the ageing brain: current evidence and new directions. Proc Nutr Soc. 2018;77: 152-63. https://doi.org/10.1017/s0029665117004177.

18. Innis SM. Dietary omega 3 fatty acids and the developing brain. Brain Res. 2008;1237:35-43. https://doi.org/10.1016/j.brainres.2008.08.078.

19. Farquharson J, Cockburn F, Patrick WA, Jamieson EC, Logan RW. Infant cerebral cortex phospholipid fatty-acid composition and diet. Lancet. 1992; 340:810-3.

20. Oken E, Osterdal ML, Gillman MW, Knudsen VK, Halldorsson TI, Strom M, et al. Associations of maternal fish intake during pregnancy and breastfeeding duration with attainment of developmental milestones in early childhood: a study from the Danish National Birth Cohort. Am J Clin Nutr. 2008;88:789-96. https://doi.org/10.1093/ajcn/88.3.789.

21. van de Rest O, Berendsen AA, Haveman-Nies A, de Groot LC. Dietary patterns, cognitive decline, and dementia: a systematic review. Adv Nutr. 2015:6:154-68. https://doi.org/10.3945/an.114.007617.

22. Rupp H, Turcani M, Ohkubo T, Maisch B, Brilla CG. Dietary linolenic acidmediated increase in vascular prostacyclin formation. Mol Cell Biochem. 1996;162:59-64

23. Sheppard KW, Cheatham CL. Executive functions and the omega-6-toomega-3 fatty acid ratio: a cross-sectional study. Am J Clin Nutr. 2017;105: 32-41. https://doi.org/10.3945/ajcn.116.141390.

24. Blasbalg TL, Hibbeln JR, Ramsden CE, Majchrzak SF, Rawlings RR. Changes in consumption of omega-3 and omega- 6 fatty acids in the United States during the 20th century. Am J Clin Nutr. 2011;93:950-62. https://doi.org/10. 3945/ajcn.110.006643.

25. Cunnane SC, Schneider JA, Tangney C, Tremblay-Mercier J, Fortier M, Bennett DA, et al. Plasma and brain fatty acid profiles in mild cognitive impairment and Alzheimer's disease. J Alzheimers Dis. 2012;29:691-7. https://doi.org/10.3233/jad-2012-110629.

26. Samieri C, Feart C, Letenneur L, Dartigues JF, Peres K, Auriacombe S, et al. Low plasma eicosapentaenoic acid and depressive symptomatology are independent predictors of dementia risk. Am J Clin Nutr. 2008;88:714-21. https://doi.org/10.1093/ajcn/88.3.714. 
27. Vercambre MN, Boutron-Ruault MC, Ritchie K, Clavel-Chapelon F, Berr C. Long-term association of food and nutrient intakes with cognitive and functional decline: a 13-year follow-up study of elderly French women. $\mathrm{Br}$ J Nutr. 2009;102:419-27. https://doi.org/10.1017/s0007114508201959.

28. Andruchow ND, Konishi K, Shatenstein B, Bohbot VD. A lower ratio of omega-6 to omega-3 fatty acids predicts better hippocampus-dependent spatial memory and cognitive status in older adults. Neuropsychology. 2017; 31:724-34. https://doi.org/10.1037/neu0000373.

29. Kalmijn S, Feskens EJ, Launer $\amalg$, Kromhout D. Polyunsaturated fatty acids, antioxidants, and cognitive function in very old men. Am J Epidemiol. 1997; 145:33-41. https://doi.org/10.1093/oxfordjournals.aje.a009029.

30. Beydoun MA, Kaufman JS, Sloane PD, Heiss G, Ibrahim J. N-3 fatty acids, hypertension and risk of cognitive decline among older adults in the atherosclerosis risk in communities (ARIC) study. Public Health Nutr. 2008;11: 17-29. https://doi.org/10.1017/\$1368980007000080.

31. Arendash GW, Jensen MT, Salem N Jr, Hussein N, Cracchiolo J, Dickson A, et al. A diet high in omega-3 fatty acids does not improve or protect cognitive performance in Alzheimer's transgenic mice. Neuroscience. 2007; 149:286-302. https://doi.org/10.1016/j.neuroscience.2007.08.018.

32. Centers for Disease, Control, and Prevention. National Health and Nutrition Examination Survey. Survey Methods and Analytic Guidelines https://www. cdc.gov/nchs/nhanes/index.htm Accessed 15 January 2020.

33. Centers for Disease, Control, and Prevention. National Health and Nutrition Examination Survey. Questionnaires, Datasets, and Related Documentation. https://wwwn.cdc.gov/nchs/ Accessed 15 January 2020.

34. Fillenbaum GG, van Belle G, Morris JC, Mohs RC, Mirra SS, Davis PC, et al, Consortium to establish a registry for Alzheimer's disease (CERAD): the first twenty years. Alzheimers Dement. 2008;4:96-109. https://doi.org/10.1016/j. jalz.2007.08.005

35. Gao S, Jin Y, Unverzagt FW, Liang C, Hall KS, Ma F, et al. Hypertension and cognitive decline in rural elderly Chinese. J Am Geriatr Soc. 2009;57:1051-7. https://doi.org/10.1111/j.1532-5415.2009.02267.x.

36. Clark LJ, Gatz M, Zheng L, Chen YL, McCleary C, Mack WJ. Longitudinal verbal fluency in normal aging, preclinical, and prevalent Alzheimer's disease. Am J Alzheimers Dis Other Dement. 2009;24:461-8. https://doi.org/ 10.1177/1533317509345154.

37. Canning SJ, Leach L, Stuss D, Ngo L, Black SE. Diagnostic utility of abbreviated fluency measures in Alzheimer disease and vascular dementia. Neurology. 2004;62:556-62. https://doi.org/10.1212/wnl.62.4.556.

38. Jaeger J. Digit symbol substitution test: the case for sensitivity over specificity in neuropsychological testing. J Clin Psychopharmacol. 2018;38: 513-9. https://doi.org/10.1097/jcp.0000000000000941.

39. Qin B, Xun P, Jacobs DR Jr, Zhu N, Daviglus ML, Reis JP, et al. Intake of niacin, folate, vitamin B-6, and vitamin B-12 through young adulthood and cognitive function in midlife: the coronary artery risk development in young adults (CARDIA) study. Am J Clin Nutr. 2017;106:1032-40. https://doi.org/10. 3945/ajcn.117.157834.

40. National Health and Nutrition Examination Survey 2013-2014 Data Documentation, Codebook, and Frequencies, Cognitive Functioning (CFQ_ H) https://wwwncdcgov/Nchs/Nhanes/2013-2014/CFQ_Hhtm\#CFDDS Accessed 30 January 2020.

41. Chen SP, Bhattacharya J, Pershing S. Association of Vision Loss with Cognition in older adults. JAMA Ophthalmol. 2017;135:963-70. https://doi. org/10.1001/jamaophthalmol.2017.2838.

42. The examination protocol and data collection methods. https://wwwn.cdc. gov/nchs/data/nhanes/2011-2012/manuals/mec_in_person_dietary_ procedures_manual_jan_2012.pdf Accessed 31 January 2020.

43. Chen J, Sun B, Zhang D. Association of Dietary n3 and n6 Fatty Acids Intake with Hypertension: NHANES 2007-2014. Nutrients. 2019:11. https://doi.org/ 10.3390/nu11061232.

44. U.S. Department of Agriculture, Agricultural Research Service. Usda Food and Nutrient Database for Dietary Studies. https:/Www.Cdc.Gov/Nchs/ Tutorials/Dietary/Surveyorientation/ Accessed 15 January 2020.

45. National Health and Nutrition Examination Survey, 2013-2014 Data Documentation, Codebook, and Frequencies Physical Activity (PAQ_H) https://wwwncdcgov/Nchs/Nhanes/2013-2014/PAQ_Hhtm\#Component_ Description Accessed 2 February 2020.

46. Centers for Disease, Control, and Prevention. National Health and Nutrition Examination Survey. Demographic data and Related Documentation. https://wwwn.cdc.gov/Nchs/Nhanes/2011-2012/DEMO_G.htm\#INDFMPIR Accessed 1 February 2020.
47. National Health and Nutrition Examination Survey. Tutorials. Module 3 : Weighting. https://wwwn.cdc.gov/nchs/nhanes/tutorials/module3.aspx Accessed 3 February 2020.

48. GS ON. A procedure to tabulate and plot results after flexible modeling of a quantitative covariate. Stata Journal. 2011;11:1-29.

49. Ganguli M, Snitz BE, Lee CW, Vanderbilt J, Saxton JA, Chang CC. Age and education effects and norms on a cognitive test battery from a populationbased cohort: the Monongahela-Youghiogheny healthy aging team. Aging Ment Health. 2010;14:100-7. https://doi.org/10.1080/13607860903071014.

50. Fotuhi M, Mohassel P, Yaffe K. Fish consumption, long-chain omega-3 fatty acids and risk of cognitive decline or Alzheimer disease: a complex association. Nat Clin Pract Neurol. 2009;5:140-52. https://doi.org/10.1038/ ncpneuro1044.

51. Kalmijn S, Launer $L$, Ott A, Witteman JC, Hofman A, Breteler MM. Dietary fat intake and the risk of incident dementia in the Rotterdam study. Ann Neurol. 1997;42:776-82. https://doi.org/10.1002/ana.410420514.

52. Chiu CC, Su KP, Cheng TC, Liu HC, Chang CJ, Dewey ME, et al. The effects of omega-3 fatty acids monotherapy in Alzheimer's disease and mild cognitive impairment: a preliminary randomized double-blind placebo-controlled study. Prog Neuro-Psychopharmacol Biol Psychiatry. 2008;32:1538-44. https://doi.org/10.1016/j.pnpbp.2008.05.015.

53. Das UN. Folic acid and polyunsaturated fatty acids improve cognitive function and prevent depression, dementia, and Alzheimer's disease--but how and why? Prostaglandins Leukot Essent Fatty Acids. 2008;78:11-9. https://doi.org/10.1016/j.plefa.2007.10.006.

54. Sheppard KW, Cheatham CL. Omega-6/omega-3 fatty acid intake of children and older adults in the U.S.: dietary intake in comparison to current dietary recommendations and the Healthy Eating Index. Lipids Health Dis. 2018;17:43. https://doi.org/10.1186/s12944-018-0693-9.

55. Agrawal R, Gomez-Pinilla F. 'Metabolic syndrome' in the brain: deficiency in omega-3 fatty acid exacerbates dysfunctions in insulin receptor signalling and cognition. J Physiol. 2012;590:2485-99. https://doi.org/10.1113/jphysiol.2012.230078.

56. Hirashima F, Parow AM, Stoll AL, Demopulos CM, Damico KE, Rohan ML, et al. Omega-3 fatty acid treatment and T(2) whole brain relaxation times in bipolar disorder. Am J Psychiatry. 2004;161:1922-4. https://doi.org/10.1176/ ajp.161.10.1922.

57. Hashimoto M, Hossain S. Neuroprotective and ameliorative actions of polyunsaturated fatty acids against neuronal diseases: beneficial effect of docosahexaenoic acid on cognitive decline in Alzheimer's disease. J Pharmacol Sci. 2011;116:150-62.

58. Boneva NB, Kikuchi M, Minabe Y, Yamashima T. Neuroprotective and ameliorative actions of polyunsaturated fatty acids against neuronal diseases: implication of fatty acid-binding proteins (FABP) and G proteincoupled receptor 40 (GPR40) in adult neurogenesis. J Pharmacol Sci. 2011; 116:163-72.

59. Calderon F, Kim HY. Role of RXR in neurite outgrowth induced by docosahexaenoic acid. Prostaglandins Leukot Essent Fatty Acids. 2007;77: 227-32. https://doi.org/10.1016/j.plefa.2007.10.026.

60. Blok WL, Katan MB, van der Meer JW. Modulation of inflammation and cytokine production by dietary (n-3) fatty acids. J Nutr. 1996;126:1515-33. https://doi.org/10.1093/jn/126.6.1515.

\section{Publisher's Note}

Springer Nature remains neutral with regard to jurisdictional claims in published maps and institutional affiliations.

\section{Ready to submit your research? Choose BMC and benefit from:}

- fast, convenient online submission

- thorough peer review by experienced researchers in your field

- rapid publication on acceptance

- support for research data, including large and complex data types

- gold Open Access which fosters wider collaboration and increased citations

- maximum visibility for your research: over $100 \mathrm{M}$ website views per year

At $\mathrm{BMC}$, research is always in progress.

Learn more biomedcentral.com/submissions 